\title{
MANAGEMENT OF TETANUS NEONATORUM WITH INTERMITTENT POSITIVE-PRESSURE RESPIRATION
}

BY

\author{
N. M. MANN, B. G. JACKSON and R. HOLLOWAY \\ From the Department of Medicine, and the Department of Paediatrics and Child Health, \\ University of Natal, and King Edward VIII Hospital, Durban
}

(RECEIVED FOR PUBLICATION NOVEMBER 14, 1962)

A previous report from this hospital on the treatment of severe tetanus neonatorum (Wright, Sykes, Jackson, Mann and Adams, 1961) showed that intermittent positive pressure respiration (I.P.P.R.) significantly lowered the mortality rate. Only 11 babies died in a group of 25 treated by this technique (mortality rate $44 \%$ ) as against 21 out of 25 babies treated by combinations of chlorpromazine and barbiturates (mortality rate $84 \%$ ). These results also compared favourably with mortality rates of $92 \%$ (Gek, 1951) and $82.5 \%$ (Wright, $1960 a)$ in two large series of cases treated conservatively by sedation.

Further experience gained in this hospital from the use of I.P.P.R. in a total of 71 babies has led to a further lowering of the overall mortality rate to $29 \%$.

The purpose of this paper is to describe the details of organization and management of severe tetanus neonatorum by total paralysis and I.P.P.R.

\section{Accommodation and Staff}

Alterations were made to a suitable side ward to provide a wash-hand basin, three electric points for the Radcliffe respirators (Mark V) and a piped oxygen supply. Wooden rails on two opposite walls carried the patients' charts and the oxygen flowmeters (Fig. 1).

A medical officer is on duty in the ward or available at short notice. The African nursing staff were trained by him. A staff of at least three nurses are always in the ward to allow for emergencies. Three nurses are necessary for the first baby on I.P.P.R. and then one extra nurse for every additional two patients admitted.

\section{Medical Management}

Standardized Treatment. On admission, all babies have intramuscular injections of antitetanus serum
$(50,000$ units) and vitamin $\mathrm{K}(1 \mathrm{mg}$.). Liquid paraffin $(2 \mathrm{ml}$.) is given every day from the beginning to prevent constipation. A course of penicillin is prescribed for 10 days during the period of curarization. Pathogenic organisms found in the tracheal secretions were sensitive to chloramphenicol more often than to other antibiotics and the change to this drug was made when it became necessary. Before discharge tetanus toxoid $(0.5 \mathrm{ml}$.) is injected intramuscularly and the child is seen afterwards in the follow-up clinic for further active immunization.

Respirator. Frequent and severe spasms justify treatment by mechanical respiration (Wright et al., 1961). An oral endotracheal tube is inserted after relaxation with intramuscular succinylcholine (20 mg.), and respiration is continued with a Radcliffe respirator (Mark V) which stands on a pedestal 12 in. $(30.5 \mathrm{~cm}$.) high. The air inlet of the machine is raised 30 in. $(76 \mathrm{~cm}$.) off the floor by a fitted anaesthetic tube attached to the top of the respirator to reduce the dust intake.

Tracheostomy. Tracheostomy is performed at the level of the fourth, fifth and sixth tracheal rings by making a vertical incision $5 \mathrm{~mm}$. in length. Initially, a size 00 , nylon-reinforced latex tube, shortened to 6.0 to $6.5 \mathrm{~cm}$. is inserted into the trachea of all newborn babies between $3.5 \mathrm{lb} .(1.6 \mathrm{~kg}$.) and $7 \cdot 5 \mathrm{lb} .(3 \cdot 4 \mathrm{~kg}$.) in weight. After a few days it is usually necessary to substitute a size 0 tube to maintain the airtight fit. Care is taken to avoid anoxia during the change-over from the oral to the tracheostomy tube. The oral tube has to be withdrawn a little to allow the introduction of the tracheostomy tube, but it must remain in the trachea to ventilate the apnoeic infant until the tracheostomy tube has been placed in position. The correct site of the lower end of the tube is determined by pushing it as far as the carina and then withdrawing it until inspection and auscultation 


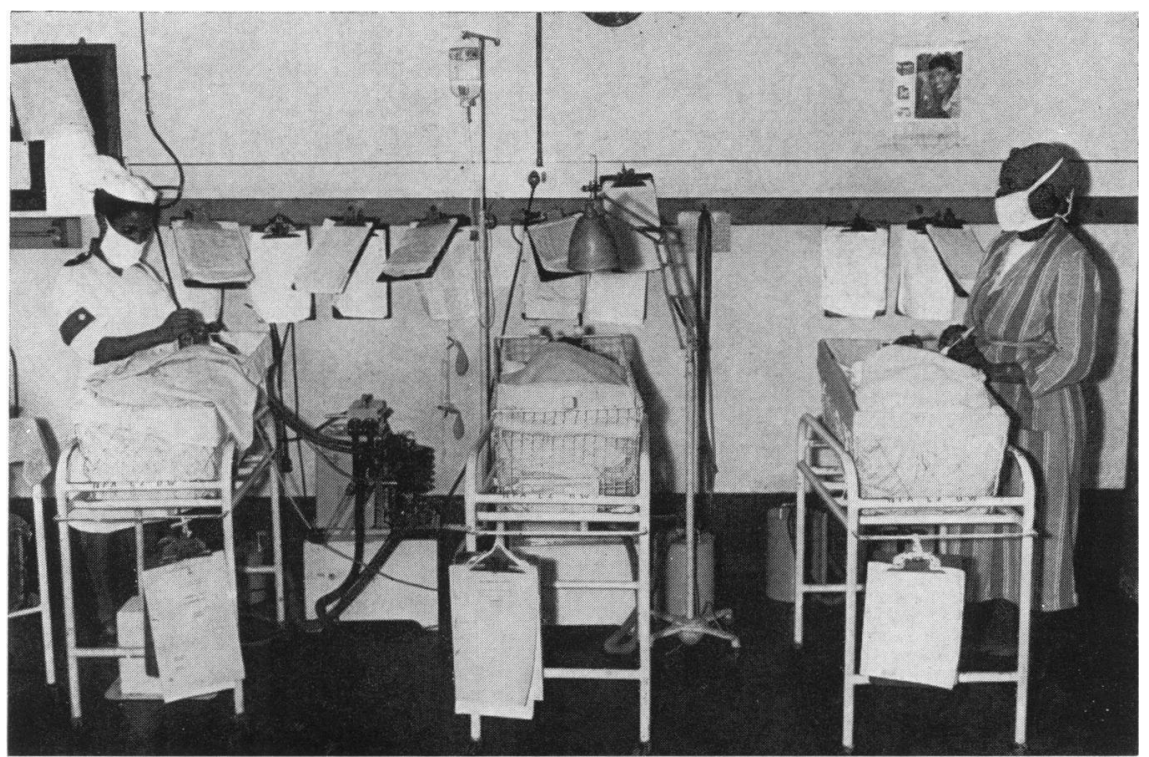

FIG. 1 above.-A general view of the ward.

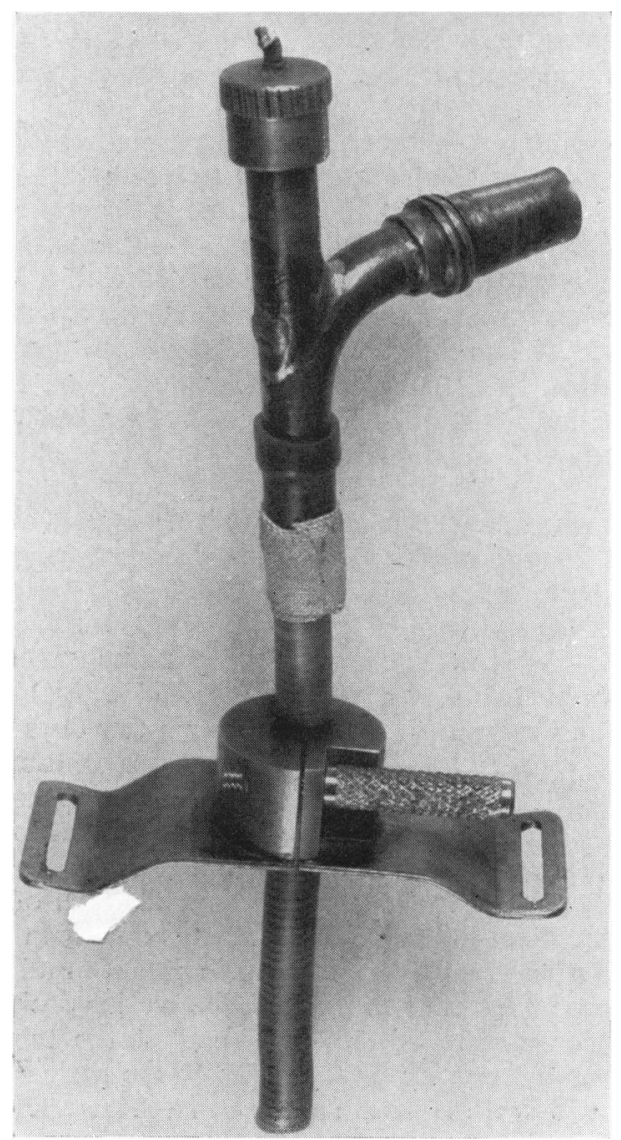

FIG. 2.-The suction T-piece and latex tube enclosed in the screwclamp. The tapes of an improvised harness are attached to the holes in the base-plate.

confirm that both lungs are being properly ventilated. The tube is connected to a suction T-piece, the junction being reinforced with a narrow strip of 'elastoplast' to withstand the movement and tension (Fig. 2). Finally, the tube is stabilized with a screw clamp and harness (Sykes, 1960a). The clamp encircles $1 \mathrm{~cm}$. of the latex tube which projects about $2 \mathrm{~cm}$. above it, and passes through $1 \cdot 25 \mathrm{~cm}$. of the interposed dressing and the soft tissues of the neck. Thus, it could be estimated that a tube $6.5 \mathrm{~cm}$. in length, which emerged $2.25 \mathrm{~cm}$. above the clamp, extended $2.0 \mathrm{~cm}$. into the trachea. The latex tube is ringed with ink above the clamp so that it is possible to recognize any subsequent slipping of the tube, which might account for reduced air entry to a lung.

A simple harness is improvised by applying waterproof strapping to two lengths of 'tubagauz' or rolled cottonwool. At the ends of these two straps holes are made through which half-inch linen tapes are looped. The upper strap passes behind the neck. The lower one is placed across the back and under the axillae. The free ends of the tapes are threaded through the holes of the clamp base plate and tied (Fig. 3).

Humidification. The essence of management of tetanus neonatorum during I.P.P.R. is the preven- 


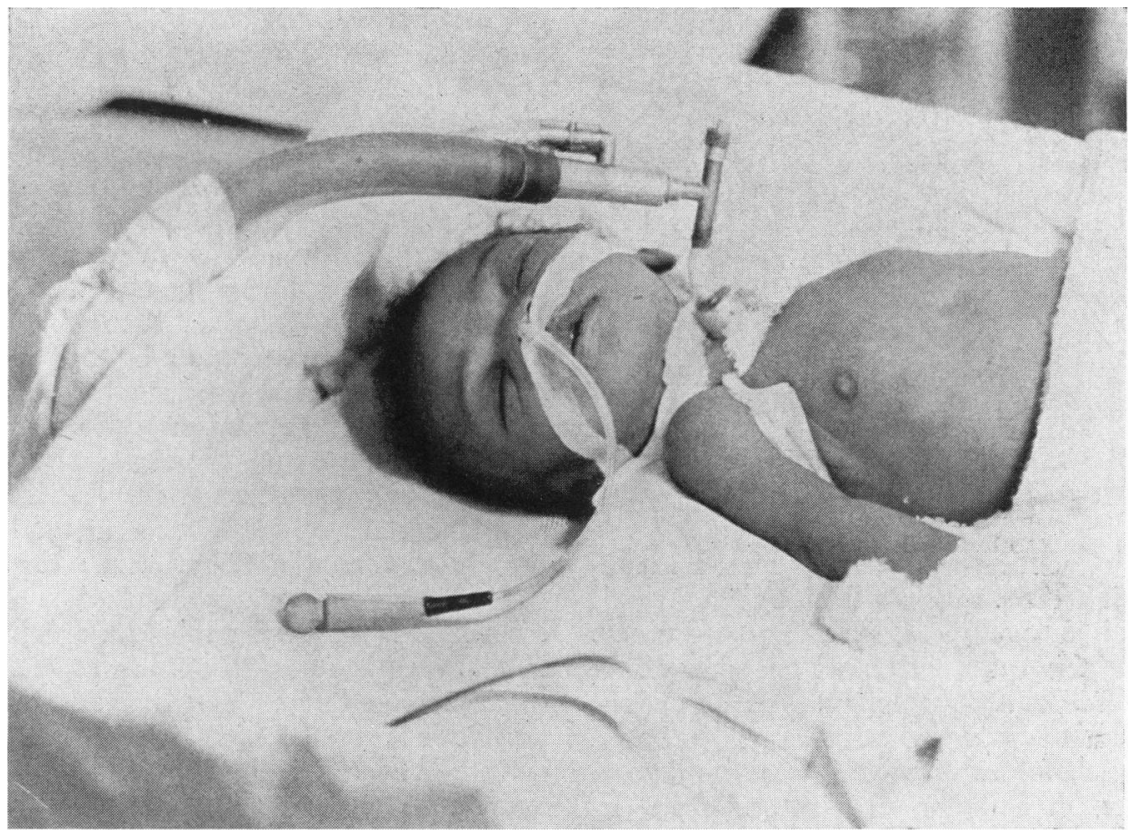

Fig. 3.-Tre tracheostomy assembly kept in position by the shoulder harness.

tion of pulmonary infection and atelectasis. An attempt is being made to replace the physiological protective mechanisms by artificial methods. Humidifying the inspired air maintains the moisture and movement of lung secretions so that they can be aspirated easily.

During the treatment of the earlier cases in this unit, the gases delivered by the respirator were warmed to body temperature with a thermostatically controlled water-bath. Considerable cooling of the gas occurred between the humidifier and the patient, particularly as the volume of gas at each inflation was so small. Consequently, it was sometimes necessary to heat the water-bath to temperatures as high as $160^{\circ} \mathrm{F}$. $\left(71 \cdot 1^{\circ} \mathrm{C}\right.$.). In later cases the humidifier has been set at body temperature and the gas delivered at room temperature. No harmful results have been noted from this procedure, although it must be remembered that Durban is a coastal town with a high humidity.

Control of Ventilation. The inflation rate of the respirator is set at 37 per minute, and the inflation pressure is adjusted to maintain the arterial carbon dioxide tension $\left(\mathrm{PCO}_{2}\right)$ as near to the normal values as possible. The $\mathrm{PCO}_{2}$ is measured by the rebreathing method first described by Plesch (1909). The rebreathing bag is reduced to $100 \mathrm{ml}$. (Fig. 4), the period of initial rebreathing to 60 seconds and the equilibration periods to 10 seconds (Sykes, 1960b). Carbon dioxide estimations are made with the modified Haldane apparatus (Campbell, 1960).

Changes in total thoracic compliance provide useful help in the assessment of alterations in the efficiency of ventilation. To measure compliance the supine baby is disconnected from the respirator and when the chest has resumed the resting position a known volume of air is introduced into the lungs with a $50-\mathrm{ml}$. syringe. The resulting static pressure

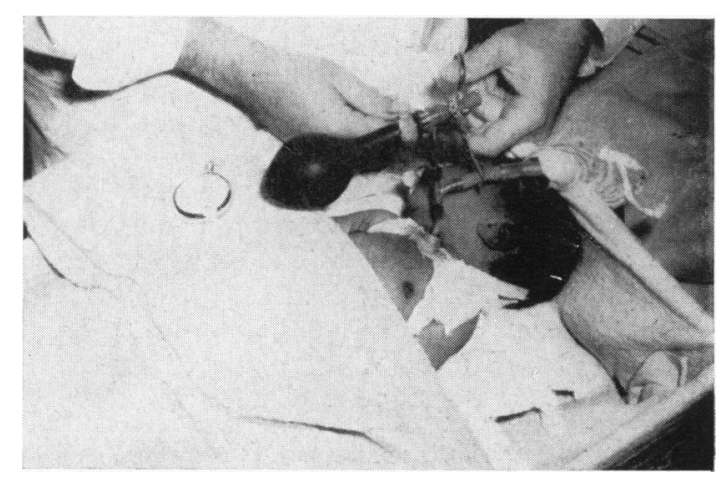

FIG. 4.-The rebreathing method for estimating the $\mathrm{PCO}_{2}$. 


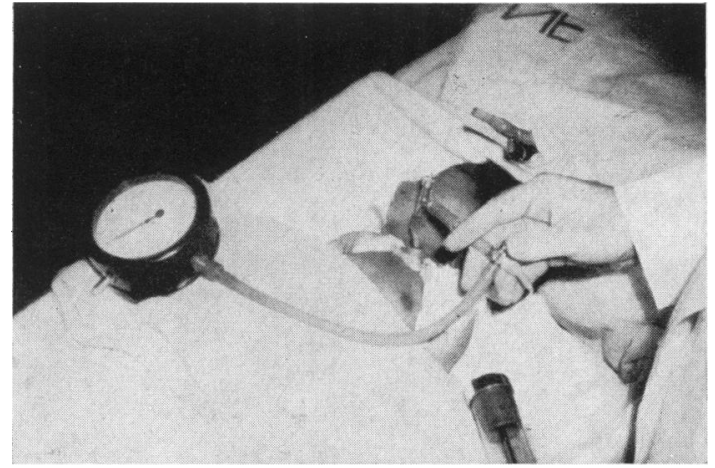

FIG. 5.-Disconnexion from the respirator for measurement of lung compliance.

is measured by connecting the lungs with a manometer through a three-way tap (Fig. 5).

In practice it is usually only necessary to estimate the $\mathrm{PCO}_{2}$ routinely once a day, which takes about 15 minutes. Subsequent compliance measurements, which take about one to two minutes, are sufficient to detect any significant change in the ventilation. Any reduction in compliance is accompanied by a rise in the $\mathrm{PCO}_{2}$ level.

In infants the efficiency of ventilation cannot be assessed accurately from chest movements or by other bedside observations. It is always necessary to measure the $\mathrm{PCO}_{2}$ and/or arterial oxygen saturation. The values for the $\mathrm{PCO}_{2}$ have varied from 6.1 to $80.0 \mathrm{~mm}$. $\mathrm{Hg}$, and the extremes of $\mathrm{PCO}_{2}$ have usually been unsuspected. In adults, sweating, tachycardia and a bounding pulse are usually evident when the $\mathrm{PCO}_{2}$ has risen to between 45 and $50 \mathrm{~mm}$. $\mathrm{Hg}$. The routine measurement of blood pressure is technically easier in older patients, and a rise in pressure is a valuable indication of a rise in the $\mathrm{PCO}_{2}$.

Curarization. Total paralysis is maintained by the intermittent injection of $3 \mathrm{mg}$. d-tubocurarine intramuscularly as required, the daily dose varying from 6 to $48 \mathrm{mg}$.

Assisted Respiration. The problem of how long to continue mechanical respiration was discussed by Wright et al. (1961). Although spasms diminish in intensity and frequency, in severe cases they are often still present during the third and fourth weeks after the onset. Tracheal suction is a particular threat to the baby because a bout of spasms can be precipitated at a time when suction has removed air from the lungs. Periods of cyanosis or apnoea are common at this time. Therefore, when curarization has been stopped between the 10th and 12th day after the start of I.P.P.R., a method of assisted respiration is continued during the third week.

The screw-cap of the Cobb-type endotracheal connexion is removed so that an aperture $3-4 \mathrm{~mm}$. in diameter is open to the air at one end of the tracheostomy tube. The inflation rate of the respirator is reduced, and the baby can make up the deficit in mechanical ventilation by spontaneous breaths between inflations of the respirator. The bellows of most respirators are large enough to compensate for this leak, and are thus able to produce any inflation pressure required. Additional weights are added to the bellows of the Radcliffe respirator to produce the required pressure.

When the rate of the respirator is 15 to 20 per minute, the baby takes one, two or three spontaneous breaths between the mechanical inflations. By fitting a corrugated tube around the chest, and connecting this tube to a tambour and lever, the respiratory movements of the chest during assisted respiration can be demonstrated on a moving drum. A pneumograph obtained in this way was recorded from a baby 15 days after the onset of spasms, and 34 hours after the last dose of d-tubocurarine (Fig. 6). The square waves pointing

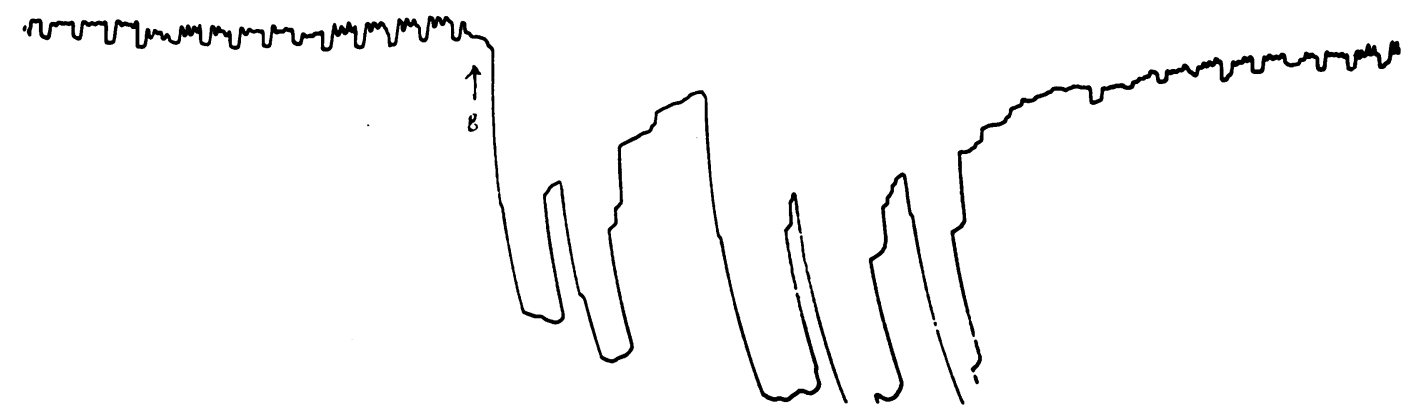

Fig. 6.-A pneumograph taken during assisted respiration. The square waves pointing downwards represent the chest movements produced by the respirator. The smaller waves between the larger strokes represent the baby's respiratory excursions. A series of spasms is recorded in the centre of the figure. 
downwards represent the chest movements produced by the respirator, at the rate of 18 per minute. The smaller waves between the larger strokes represent the baby's respiratory excursions. A series of spasms, lasting about one minute, is recorded in the centre of the Figure. Spontaneously breathing babies often suffer from anoxia by the end of such spasms, and sometimes stop breathing. The principal purpose of assisted respiration is to maintain ventilation, particularly at the end of spasms, until the baby can resume respirations.

The routine estimation of $\mathrm{PCO}_{2}$ is unnecessary during assisted respiration as the appearance of the baby is a valuable aid in the assessment of respiratory function. If the face appears contented and composed, the respiratory function is normal. The contented baby 'munches' at frequent intervals, even during sleep; this is probably the sucking reflex restricted by facial rigidity. In the presence of impaired respiratory function, which at this stage is usually associated with excessive secretions or with partial obstruction of the airway, the baby appears restless and cries often. Respiratory movements require visible muscular effort. Prolonged regular inspiratory and expiratory movements replace the shallow and sometimes irregular runs of effortless breathing normally seen.

It can thus be deduced that babies having assisted respiration require less intensive care than babies having controlled I.P.P.R.

The Tracheostomy Tube in the Recovery Period. When mechanical ventilation has ceased, the tracheostomy tube is still necessary during the recovery period because muscular rigidity, minor spasms and dysphagia may continue for four to five weeks. At the end of assisted respiration, the clamp and suction T-piece are removed from the tracheostomy assembly. They are replaced by a standard metal tracheostomy tube modified by shortening the shaft and removing the caudal projection of the flange (Fig. 7). The latex tube, of suitable size to give a snug fit, is drawn through the stub of this metal tube (Fig. 8). About $0.5 \mathrm{~cm}$. of the latex tube projects above the plate with the airway guard inserted into its upper end. The flange is secured by tapes tied firmly around the flexed neck, and triple-knotted posteriorly in the midline, with the ends of the tape left long.

Removal of the Tracheostomy Tube. Initial difficulties with removal of the tracheostomy tube appeared to be the result of inspiratory collapse of the trachea at the site of the tracheostomy. However, since the vertical incision of the lower

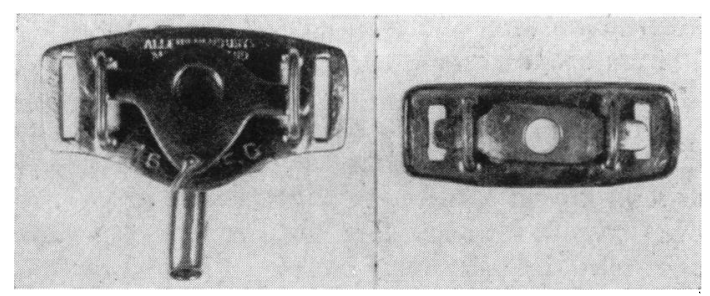

FIG. 7.-A standard metal tracheostomy tube is modified by shortening the shaft and removing the caudal projection of the flange.

tracheal rings has replaced the 'window' tracheostomy, these difficulties have been much less. Nevertheless, in view of the risk of acute respiratory obstruction developing suddenly, the removal of the tube must be regarded as a major procedure; and a sterile tracheostomy tube, good lighting and a competent staff should be available for the next 24 hours.

Oral feeding has already been established before an attempt is made about the 21 st day to remove the tube. This is best done early in the morning between feeds when the appetite has been satisfied and the baby is not likely to cry from hunger. After removal of the tube, the baby usually refuses the next one or two feeds but quickly settles down to resume normal feeding.

If the baby shows signs of partial respiratory

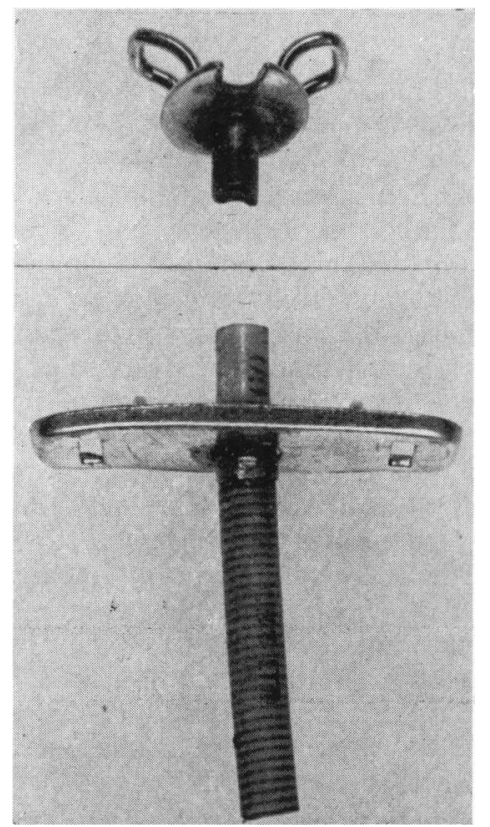

Fig. 8.-The nylon-reinforced latex tube is drawn through the stub of the modified metal tracheostomy tube. The airway guard is inserted into the upper end of the latex tube. 
obstruction after the tube has been out for five to 10 minutes, the tube is reinserted and left for several days.

When the tube has to be replaced after being out for some hours, an acute emergency has usually arisen. Some degree of obstruction may have been present for some time but stronger respiratory efforts by the baby have converted partial obstruction to complete collapse of the trachea. Under these circumstances, a metal tracheostomy tube (No. 16 F.G.), with introducer in place, is inserted exactly over the ostium which has often contracted down to a pin point in the centre of scar tissue. The tip of the tube is directed backwards towards the vertebral column. Sufficient force has to be exerted to push the tip of the tube through the contracted ostium. Once through the ostium, the tube passes down the track into the trachea.

The use of sedatives may be misleading. The quiet respirations which they induce suggest that the baby is managing well without the tracheostomy. When the sedation wears off, strong respiratory efforts and crying are apt to precipitate sudden respiratory obstruction at a time when the tube is difficult to reinsert.

If removal of the tube fails the first time, subsequent attempts are made at weekly intervals. Trauma is thus minimized and the infant tends to outgrow the tracheostomy. No failures have occurred since the case reported previously (Wright et al., 1961).

\section{Problems in Management of Intermittent Positive Pressure Respiration}

Surgical Emphysema. Pneumothorax occurred in three babies during treatment with I.P.P.R. In these three babies and in the young patients reported by Hay (1954) and Lawes and Harries (1956) the probable mechanism of this complication was overdistension and subsequent rupture of the lung alveoli from excessive pressure by manual inflation. Air may pass through the ruptured bases of the alveoli into adjacent pulmonary vascular sheaths. This pulmonary interstitial emphysema may become extensive enough to splint the lungs. Under pressure, air may track along the sheaths to the mediastinum and then between the fascial planes into the neck; it may rupture into the pleural cavities (Macklin and Macklin, 1944) or pass down around the aorta and oesophagus into the retroperitoneal tissues; in the mediastinum air also interferes with the return of venous blood to the heart.

In this unit manual inflation is used during I.P.P.R. in the course of $\mathrm{PCO}_{2}$ estimations, during weighing, and in emergencies to inflate the lungs with pure oxygen. The greatest care is taken to instruct the nursing staff in the safe use of an openended B.L.B. reservoir bag to ventilate the babies' lungs with gentle inflations at a rapid rate.

Pneumothorax developed in another two cases when the babies were breathing spontaneously through their tracheostomy tubes in the presence of respiratory obstruction. It is possible that air was sucked into the mediastinum through the opened cervical tissue planes (Forbes and Salmon, 1943; Forbes, Salmon and Herweg, 1947).

The commonest clinical signs that we encountered in tension pneumothorax were cyanosis, abdominal distension and increased resistance to inflation of the lungs. Radiography of the chest and abdomen may aid in the diagnosis but there is not time for this if tension pneumothorax has occurred during I.P.P.R. The tension pneumothorax is relieved by inserting a needle, and later a catheter, into the pleural cavity through the second or third intercostal space anteriorly. The catheter is connected to an underwater drainage tube.

Three babies survived a tension pneumothorax with this method of treatment. Air continued to bubble through the drainage tube for two days during treatment with I.P.P.R., which had to be prolonged. Whenever the drainage tube blocked, the abdomen became distended and the resistance to inflation increased. The tube was finally removed successfully and the babies recovered completely.

Oedema. Oedema is a conspicuous feature in newborn babies during the first few days of treatment with I.P.P.R. The clinical manifestations are a rise in weight and an increase in the elastic resistance to inflation of the lungs which therefore require a higher inflation pressure. This resistance becomes less when the oedema decreases after seven days. Several factors may have contributed to its formation (Astrup, Gøtzche and Neukirch, 1954; Drury, Henry and Goodman, 1947), but the cause is not yet understood. However, pulsatile I.P.P.R. (Love, Roddie, Rosensweig and Shanks, 1957) now being tried in this unit may reduce its incidence.

Constipation. Motility of the gastro-intestinal tract is diminished during I.P.P.R. and curarization, with a varying delay in gastric emptying time. Occasionally this has progressed to paralytic ileus. Despite the use of breast milk, constipation may occur and even impaction of faeces, requiring digital removal. However, we have learned to 
avoid this complication by daily dosage with liquid paraffin and by reducing the intake of feeds when gastric residue shows signs of increasing.

\section{Nursing Duties}

Posture. Nursing the baby on a 'mattress' of blankets and pillows packed to the top of a wiremesh bassinet has many advantages. In this way the baby is easily accessible. The weight of the plastic respirator tubing is taken by the top edge of the bassinet to which it is tied; the respirator tubing does not have to dip down and its alignment with the baby is readily seen, so avoiding torque and spring on the tracheostomy. Harnessed to the respirator, the baby lies naked on a napkin, covered by light woollen blankets. Premature babies are best nursed with the additional protection of a vest improvised from about two turns of flannel bandage. Every effort is made to reduce exposure to a minimum because of the excessive fall in body temperature that can occur. Extra warmth can be provided by the light from an angle-poise lamp or from a small electric pad placed on top of the blankets.

The bassinet is placed with a 15-degree head-up tilt except when physiotherapy is being performed. The baby lies with the head extended and at a lower level than the trunk. This ensures that pharyngeal secretions drain away from the larynx.

To prevent atelectasis the baby is turned regularly from the supine to the right and then to the left half lateral positions every hour.

Physiotherapy. The nursing staff perform the hourly physiotherapeutic routine which was originally taught them by physiotherapists. The routine is designed to replace the cough by dislodging mucus and secretions from the bronchi into the trachea where they are aspirated.

Protected by a thin blanket, the chest is percussed with the extended fingers for several minutes at a time with the baby in the prone, supine, lateral, head-up and head-down positions. Pressing and squeezing the chest are also effective methods, but were abandoned after ribs were fractured.

Suction Technique. Bronchial secretions are usually scanty for an initial period of about 12 hours after I.P.P.R. has started. Secretions obstruct the narrower air passages in babies sooner than in adults and impair ventilation. Consequently physiotherapy and suction are required at hourly intervals.

With strict attention to asepsis, bronchial secretions are aspirated through a sterile soft rubber catheter (No. 3 E.G.) and suction is applied only on withdrawal. In this way the tracheal mucosa is less likely to be damaged with the risk of bleeding, clot formation and respiratory obstruction. The procedure is carried out rapidly to minimize the period of anoxia during suction.

The nursing staff are taught to use the stethoscope so that they can auscultate the lungs to confirm the removal of secretions. Persistence of adventitious sounds or reduced air entry demands a repetition of physiotherapy and suction at the affected site, or perhaps readjustment of the tracheostomy tube.

A plentiful supply of catheters is kept, with a bowl of water on a sterile trolly reserved for the purpose. A glass connexion between the catheter and the rubber tubing of the suction machine allows observation of the secretions and any change from mucoid to purulent heralds the onset of pulmonary infection.

Charting. Every hour the nursing staff auscultate the heart rate, note the pressure of the respirator and change the baby's position. An approximate assessment of the amount of mucus aspirated is made. The rectal temperature is taken every four hours on a low-reading thermometer. All this information is recorded on the hourly chart and signed by the nurse responsible. The baby is weighed every day.

Feeding. The mother is also admitted to hospital so that breast feeding can continue. Feeds of undiluted expressed breast milk are given by an indwelling gastric polyethylene tube. A baby of about $7 \mathrm{lb}$. $(3 \cdot 2 \mathrm{~kg}$.) receives standard feeds of $45 \mathrm{ml}$. on the first day and afterwards $60 \mathrm{ml}$. at three-hourly intervals round the clock (or $480 \mathrm{ml}$. daily). Premature babies are given $30 \mathrm{ml}$. initially, followed by $45 \mathrm{ml}$. for eight three-hourly feeds. The stomach is aspirated before every feed to determine the residue. This is measured and returned with a volume of milk to make up the balance of the feed. A careful record is kept of intake and output. If there is an increasing gastric residue (Sykes, 1960a) the feeds are reduced in volume, or on some occasions stopped and replaced by intravenous therapy for brief periods.

The Belcroy feeder is used as an intermediate method between tube and bottle-feeding. It is more easily manipulated by the nursing staff while encouraging the baby to suck from the small, soft teat despite some degree of trismus. The nurses teach the mother to place the teat along the front of the baby's gums and then to manoeuvre the tip of the teat through the side of the mouth by simultaneously prizing open the gums with a forefinger.

At first one or two feeds a day are attempted 
with the Belcroy feeder and the remainder of the milk is given by tube. Some babies may not take the full feed for a few days. The nasogastric tube is removed as soon as possible to avoid interference with swallowing. If difficulty in sucking persists, intramuscular chlorpromazine $(12.5 \mathrm{mg}$.) may reduce the trismus and rigidity.

The management of feeding has developed a pattern that is followed in most cases. The baby is fed by nasogastric tube for the 10 days during curarization. The Belcroy feeder is introduced when assisted respiration begins, and about the fourteenth day the gastric tube is removed. The ordinary feeding bottle replaces the Belcroy feeder as the baby's intake increases. Breast feeding is started about the 21 st day after closure of the tracheostomy. On the rare occasions when artificial feeding has been needed, unsweetened evaporated milk ( $1: 3$, added sugar $3 \%)$ has been used until a change can be made to full-cream dried milk powder before discharge. A vitamin concentrate is added to feeds daily.

\section{Discussion}

To witness the dramatic change wrought by this method of treatment in the prognosis of so severe a disease has been a unique experience. Even premature infants have been successfully treated. In the series of 31 babies with tetanus reported by one of us (Jackson, 1962), five of seven premature infants recovered. The smallest infant successfully treated weighed $3 \mathrm{lb} .10 \mathrm{oz}$. (1,644 g.) and survived not only tetanus but a severe cellulitis of the lower abdominal wall. The abdomen became twice its normal size and so handicapped breathing that assisted respiration had to be resumed for a week. Another premature infant of $3 \mathrm{lb} .9 \mathrm{oz}$. $(1,615 \mathrm{~g}$.) recovered from tetanus but, after a stormy course of respiratory difficulties, died on the 45th day when the moisture trap of the respirator fell off unnoticed.

Equally impressive has been the maintenance of the babies' general condition, which has scarcely been impaired. Only three babies lost a little weight during I.P.P.R. The interruption of weight gains during the treatment was soon made up when full feeding was re-established by the fourth week. This contrasts with the hopelessness and failure of conservative management which was the only way open to us in the past. The occasional baby that was saved by skilled nursing lived a precarious existence in a marantic state, only to succumb from pneumonia some weeks later.

Let it be said at once that the success of this treatment has been achieved only by sustained concentration of both nursing and medical effort in a special unit. The death rate was high at first while the technique was being perfected (Wright et al., 1961). If the first 46 cases are divided into three periods, the progressive fall in the mortality rate is clearly demonstrated. In the first group of 15 babies from April to December 1959, there were 10 deaths; from January to June 196016 newborn babies were treated, with five deaths. Finally, in the third period from July to December 1960, only one baby died of 15 cases treated.

Since so much can go wrong in the application of these complicated techniques, it will be appreciated that it is inadvisable to treat an isolated case by this means. However, the establishment of a unit is not a formidable undertaking. The principles of care in this and other respiratory units have long been accepted. The variations in technique required for tetanus neonatorum are easily applied now that routine procedures have been pioneered by Smythe and Bull (1959), Sykes (1960a), Wright et al. (1961) and Jackson (1962). In areas where the incidence of tetanus is high, the appointment of a full-time medical officer is justified to supervise the unit and conduct research.

Several nursing problems arise in running a special unit in a busy general hospital. The training of nursing staff in this type of work is not difficult. The routine care of an infant on a respirator is so intense and repetitive that it is quickly learned. Rather it is the problems of nursing administration that require solution. Enough nurses for a 24-hour service must be obtained and trained by the medical officer in charge. The sudden transfer of trained staff with no notice, and without sufficient preparation of a deputy, may well lead to loss of life. For this reason, the unqualified nurse aide who is less likely to be moved becomes an experienced and valued member of the team.

In other countries, where there is a high incidence of tetanus, it is well worth establishing respiratory units until public health measures eradicate the disease through education and immunization (Wright, 1960b). To avoid our mistakes and to save time, the simplest plan would be an exchange of both medical and nursing staff for teaching and learning all the detailed techniques and procedures.

\section{Summary}

A detailed description is given of the treatment of tetanus neonatorum by total paralysis and intermittent positive pressure respiration.

Thanks are due to Dr. M. K. Sykes, Consultant Anaesthetist at Hammersmith Hospital, London, who came to Durban on a Wellcome Travel Grant to help establish the respiratory unit. The Research Fellowships held by Drs. Jackson and Holloway, under the 
direction of Professor E. B. Adams, were also made possible by the generosity of the Wellcome Trust. Criticism of this paper by Professor Adams and Professor H. L. Wallace is appreciated. We are grateful to Mr. R. Gowans, F.R.C.S.E., and his staff for the tracheostomies; and to Dr. T. M. Adnams, Medical Superintendent, King Edward VIII Hospital, for facilities. We also thank the matron and nursing staff for their help.

Parts of this paper were included in a thesis submitted by Dr. B. G. Jackson for the degree of M.D. in the University of London.

\section{REFERENCES}

Astrup, P., Gøtzche, H. and Neukirch, F. (1954). Laboratory investigations during treatment of patients with poliomyelitis and respiratory paralysis. Brit. med.J., 1, 780.

Campbell, E. J. M. (1960). Simplification of Haldane's apparatus for measuring $\mathrm{CO}_{2}$ concentration in respired gases in clinical practice. ibid., 1, 457.

Drury, D. R., Henry, J. P. and Goodman, J. (1947). The effects of continuous pressure breathing on kidney function. J. clin. Invest., 26, 945 .

Forbes, G. B. and Salmon, G. W. (1943). Mediastinal emphysema and pneumothorax following tracheotomy. J. Pediat., 23, 175.

, Salmon, G. and Herweg, J. C. (1947). Further observations on post-tracheotomy, mediastinal emphysema, and pneumothorax. ibid., 31, 172.
Gek, L. S. (1951). Review of tetanus neonatorum in Singapore during years 1946-1950. Med. J. Malaya, 5, 181.

Hay, P. (1954). Pneumothorax complicating intermittent positivepressure respiration. Lancet, 2, 1156.

Jackson B. G. (1962). Problems in the technique of intermittent positive-pressure respiration in the treatment of tetanus. Thesis prescribed for the Degree of Doctor of Medicine, University of prescribed

Lawes, W. E. and Harries, J. R. (1956). Intermittent positivepressure respiration: An unusual complication in an infant. Lancet, 1, 783 .

Love, A. H. G., Roddie, R. A., Rosensweig, J. and Shanks, R. G. (1957). The effect of pressure changes in the respired air on the renal excretion of water and electrolytes. Clin. Sci., 16, 281.

Macklin, M. T and Macklin C C (1944). Malignant interstitial emphysema of the lungs and mediastinum as an important occult emphysema of the lungs and mediastinum as an important occult complication in many respiratory
Medicine (Baltimore), 23,281 .

Plesch, J. (1909). Hamodynamisch Studien. Z. exp. Path. Ther., 6, 380, 484.

Smythe, P. M. and Bull, A. (1959). Treatment of tetanus neonatorum with intermittent positive-pressure respiration. Brit. med. J., 2, 107.

Sykes, M. K. (1960a). Intermittent positive pressure respiration. In tetanus neonatorum. Anaesthesia, 15, 401.

(1960b). Observations on a rebreathing technique for the determination of arterial $\mathrm{PCO}_{2}$ in the apnoeic patient. Brit. determination of arter
$J$. Anaesth., 32, 256.

Wright, R. (1960a). Tetanus neonatorum. S. Afr. med. J., 34, 111 (1960b). The treatment of tetanus neonatorum. Thesis prescribed for the Degree of Doctor of Medicine, University of Cape Town.

Sykes, M. K., Jackson, B. G., Mann, N. M. and Adams, E. B (1961). Intermittent positive-pressure respiration in tetanus neonatorum. Lancet, $2,678$. 